\title{
Prevalence of hepatitis $B$ and delta according to HIV-type: a multi-country cross-sectional survey in West Africa
}

Patrick A. Coffie ${ }^{1,2,3^{*}}$, Boris K. Tchounga, ${ }^{3,4}$, Guillaume Bado ${ }^{5}$, Mathieu Kabran ${ }^{6}$, Daouda K. Minta ${ }^{7}$, Gilles Wandeler ${ }^{8,9}$, Geoffrey S. Gottlieb ${ }^{10}$, François Dabis ${ }^{4}$, Serge P. Eholie ${ }^{1,2,3}$ and Didier K. Ekouevi ${ }^{3,4,11}$

\begin{abstract}
Background: In West Africa where HIV-1 and HIV-2 co-circulate, the co-infection with hepatitis B virus (HBV) and hepatitis Delta virus (HDV) is not well described. This study aimed at estimating the prevalence of HBV and HBV/HDV co-infection according to HIV types and risk factors for HBV infection among West African HIV-infected patients.

Method: A cross-sectional survey was conducted within the leDEA West Africa cohort from March to December 2012 in Côte d'Ivoire (three sites), Burkina Faso and Mali (one site each). All HIV-infected adult patients on antiretroviral therapy (ART) or not who attended one of the participating HIV clinics during the study period and agreed to participate were included. Blood samples were collected and re-tested for HIV type discrimination, HBV and HDV serology as well as HBV viral load. Logistic regression was used to identify risk factors for HBV infection.

Results: A total of 791 patients were included: 192 HIV-1, 447 HIV-2 and 152 HIV-1\&2 dually reactive. At time of sampling, 555 (70.2\%) were on ART and median CD4+ cell count was 472/ $\mathrm{mm}^{3}$ (inter-quartile range [IQR]: IQR: 294-644). Sixty-seven (8.5\%, 95\% Cl 6.6-10.6) patients were HBsAg positive without any difference according to HIV type $(7.9 \%$ in HIV-1, $7.2 \%$ in HIV-1\&2 dually reactive and 9.4\% in HIV-2; $p=0.61$ ). In multivariate logistic analysis, age $\leq 30$ years old (adjusted odds ratio [aOR] 5.00, 95\% Cl 1.96-12.76), age between 31 and 49 years old (aOR 1.78, 95\% Cl 1.00-2.21) and male gender (aOR 2.15, 95\% Cl 1.25-3.69) were associated with HBsAg positivity. HBV DNA testing was performed in 36 patients with blood sample available (25 on ART) and 8 (22.2\%) had detectable HBV DNA. Among the HBsAg-positive individuals, 14.9\% (95\% Cl 7.4-25.7) were also positive for anti-HDV antibody without any difference according to HIV type (28.6\% in HIV-1, 14.3\% in HIV-2 and $0.0 \%$ in HIV-1\&2 dually reactive; $p=0.15$ ).
\end{abstract}

Conclusion: HBV and HBV/HDV co-infection are common in West Africa, irrespective of HIV type. Therefore, screening for both viruses should be systematically performed to allow a better management of HIV-infected patients. Follow-up studies are necessary to determine the impact of these two viruses on HIV infection.

Keywords: HIV-2, HBV, HBV and HDV coinfection, West Africa

\footnotetext{
*Correspondence: ahuatchi@gmail.com

'Département de Dermatologie et d'Infectiologie, UFR des Sciences

Médicales, Université Félix Houphouët Boigny, BP V3 Abidjan, CHU de

Treichville, Abidjan, Côte d'Ivoire

${ }^{2}$ Service des Maladies Infectieuses et Tropicales, Centre Hospitalier

Universitaire de Treichville, Abidjan, Côte d'lvoire

Full list of author information is available at the end of the article
} 


\section{Background}

In West Africa, approximately $8 \%$ of HIV-infected individuals have a chronic hepatitis $B$ virus (HBV) infection [1]. In this part of the world, HBV infection is one of the main causes of end-stage liver disease, cirrhosis and hepatocellular carcinoma (HCC) [2].

West Africa is also characterized by the circulation of both HIV type 1 and 2, which can to lead to co-infections with HIV-1 and HIV-2 (HIV-1\&2) [3-5]. Compared to HIV-1 infection, HIV-2 infection is characterized by a longer asymptomatic phase and a slower disease progression [6]. The management of HIV-2 infection is more challenging than the one of HIV-1, due to the intrinsic resistance of HIV-2 to non-nucleoside reverse transcriptase inhibitors (NNRTIs) and reduced sensitivity to several protease inhibitors (PIs) [7, 8].

Due to shared routes of transmission, HIV and HBV co-infection is common and 5-20\% of HIV-infected people have also chronic HBV infection worldwide [9]. Compared to HBV or HIV-mono-infected individuals, HIV/HBVco-infected patients have a higher risk of impaired immunological recovery and hepatotoxicity during antiretroviral treatment (ART) [10-12] and a faster rate of progression to cirrhosis and HCC [9]. Thus, knowledge of HBV status among HIV-infected patients is important for clinical monitoring and selection of ART, as tenofovir disoproxil fumarate (TDF) and lamivudine (3TC) or emtricitabine (FTC) should be part of the treatment [13].

In West Africa, little is known in about the epidemiology of hepatitis D virus (HDV) infection, a defective RNA virus that requires the presence of $\mathrm{HBV}$ to infect the hepatocytes [14]. Its impact on HIV/HBV co-infected patients is not documented since HDV is not routinely diagnosed. It has been estimated that approximately $5 \%$ of HBV carriers are co-infected with HDV worldwide $[15,16]$ and between $3 \%$ and $25 \%$ in West Africa [17-20]. HDV co-infection increases the risk for hepatitis flares and chronic hepatic complications $[15,21]$ and patients with HBV/HDV coinfection have a significantly increased risk for HCC compared with patients with HBV mono-infection and the general population [22]. Therefore, HDV screening is very important for the monitoring of $\mathrm{HIV} / \mathrm{HBV}$ coinfected patients.

To our knowledge, only one small-scale study from Guinea Bissau has estimated the prevalence of HDV/HBV co-infection according to HIV types and did not find any difference between HIV-1 and HIV-2 [19]. However, this needs to be confirmed with a large and multicenter study. The objectives of this study were to estimate the prevalence of HBV and HBV/HDV co-infection according to HIV types among a large series of HIV-infected patients in the WADA (West Africa Database on Antiretroviral Therapy) cohort in three West African countries and, to identify risk factors for HBV seropositivity.

\section{Methods}

\section{Study design and settings}

A cross-sectional survey was conducted from March to December 2012 in three countries (Burkina Faso, Côte d'Ivoire and Mali) within the WADA cohort. This cohort is embedded in the International epidemiological Database to Evaluate AIDS (IeDEA) West Africa Collaboration, which is part of the global IeDEA network [23].

\section{Study population}

All patients aged 18 years and above, registered in the WADA cohort as HIV-2 or dually reactive, who attended one of the participating clinics during the study period and who agreed to participate were included in this survey regardless of ART initiation according to WHO 2010 guidelines [24].

\section{Data collection}

A standardized survey form was used to collect data on patients' demographics, clinical and biological characteristics. Two EDTA tubes of blood were collected from each patient and sent to the referral laboratory of the study (CeDReS, Treichville Hospital in Abidjan, Côte d'Ivoire) to perform HIV type discrimination and hepatitis analyses.

\section{HIV retesting}

All patients identified as HIV-2 or dually reactive on clinical site according to the national algorithms were screened de novo with two immuno-enzymatic tests: Immunocomb II HIV 1 \& 2 BISPOT (Orgenics Ltd. Yavne, - Alere), a World Health Organization (WHO)-endorsed indirect, immunoenzymatic test (sensitivity 100\%; specificity 99\%) [25] and an in-house ELISA test, developed by the French National Aids and Viral Hepatitis Research Agency (ANRS) [26]. The results of this rescreening were previously reported [27]. The aim of this retesting was to perform an accurate HIV type discrimination, since HIV type misclassification has previously been reported in many West African cohorts, especially for HIV-1\&2 dually reactive patients $[27,28]$.

\section{HBV and HDV measurements}

Qualitative HBsAg was detected using Monolisa ${ }^{\circ} \mathrm{HBsAg}$ ULTRA (Bio-Rad, Evolis Tween Plus, Marnes- la- Coquette, France), a one-step sandwich enzyme immunoassay. Samples reactive for $\mathrm{HBsAg}$ were subsequently tested for $\mathrm{HBV}$ DNA and HDV serology. All tests were performed according to manufacturer's instructions. The quantitative measurement of HBV DNA in plasma was done with the COBAS $^{\circ}$ AmpliPrep/COBAS $^{\bullet}$ TaqMan $^{\bullet}$ HBV Test (Roche Molecular Systems, Inc. Roche Diagnostics GmbH). The limit of detection of this assay was $20 \mathrm{IU} / \mathrm{ml}$. Testing for anti-HDV antibody was performed using ETI-ABDELTAK-2, an enzyme immune-assay for the qualitative 
determination of total antibodies to hepatitis delta antigen (anti-HD) (DiaSorin Limited, United Kingdom).

\section{Statistical analyses}

Continuous variables were described with median and interquartile range (IQR) and categorical variables as percentages. The prevalence of HBV and HDV infections was expressed with a 95\% confidence interval (95\% CI). Group's comparisons were performed using Student's $t$ test or non-parametric Wilcoxon rank-sum test (nonnormal distribution) for continuous variables and using Chi-2 test or Fisher's exact test for categorical variables. Univariable and multivariable logistic regression analyses were performed with a stepwise-descending selection procedure to identify risk factors of $\mathrm{HBsAg}$ positivity. The selection of covariates for multivariable analysis was based on the univariable analyses with factors associated with HBsAg positivity $(p<0.25)$. Adjusted Odds Ratios (aORs) were reported with 95\% CI. We deemed a $p$ value $<0.05$ as statically significant for all analyses. Data analyses were performed using Stata software Stata $^{\mathrm{Tm}}$ 11.0 College Station, Texas, USA).

\section{Ethics}

This survey was designed and performed in accordance with the Declaration of Helsinki and was approved by the national ethics committee of each participating country: the "Comité d'Ethique pour la Recherche en Santé" (Ministry of Health and Ministry of Scientific Research and Innovation) from Burkina-Faso, the "Comité National pour l'Ethique et la Recherche en Santé" (Ministry of Health and the Fight against HIV/AIDS) from Côte d'Ivoire and the "Comité National d'Ethique pour la Santé et les Sciences de la vie (Ministry of Health)" from Mali. All patients were informed and had to give their written consent before being included.

\section{Results \\ Study population}

From March to December 2012, 791 HIV-infected patients were included in this study: 232 (29.3\%) from Burkina Faso, 535 (67.7\%) from Côte d'Ivoire and 24 (3.0\%) from Mali. After the retesting for HIV type discrimination, 192 (24.3\%) patients were classified as HIV-1, 447 (56.5\%) HIV-2 and $152(19.2 \%)$ as HIV-1\&2 dually reactive. At time of sample collection, the overall median age was 47 years [IQR): $40-$ 53], 472 (59.7\%) were women; median CD4+ cell count was 472 cells $/ \mathrm{mm}^{3}$ [IQR: 294-644]; 555 (70.2\%) were on ART, of whom $522(94.0 \%)$ had initiated a regimen composed of two nucleoside reverse transcriptase inhibitors (NRTIs) and one PI. Approximately three-quarters of patients (73.2\%) were taking an ART regimen containing 3TC (or FTC) without TDF and $21.8 \%$ an ART regimen containing TDF and 3TC (or FTC). Median duration on ART was 3.6 years
[IQR: 1.9-6.2]. Table 1 summarizes characteristics of patients at the time of blood collection.

\section{HBV serology}

Sixty-seven patients were tested positive for $\mathrm{HBsAg}$, giving an overall prevalence of $8.5 \%$ (95\% CI 6.6-10.6). HBsAg prevalence did not significantly vary according to country (9.1\% in Burkina Faso, $8.3 \%$ in Mali and $8.2 \%$ in Côte d'Ivoire, $p=0.91$ ) or HIV type (7.9\% in HIV-1, $7.2 \%$ in HIV-1\&2 dually reactive and $9.4 \%$ in HIV-2; $p=0.61$ ), but varied according to gender $(11.3 \%$ in males vs. $6.6 \%$ in females; $p=0.02$ ) (Table 2).

Among the HBsAg-positive individuals, 51 (76.1\%) were on ART: 48 (94.1\%) on a PI-based regimen, two (3.9\%) on a NNRTI-based regimen and one $(2.0 \%)$ on a triple NRTI-based regimen. Thirty-one patients (60.8\%) on ART were receiving 3TC (or FTC) without TDF and $17(33.3 \%)$ patients were on TDF + 3TC.

In multivariate analysis adjusting on HIV type, country, CD4 cell count and ART (Table 2), factors significantly associated with $\mathrm{HBsAg}$ positivity were male gender (aOR $2.15,95 \%$ CI 1.25-3.69), age $\leq 30$ years old (aOR 5.00, 95\% CI 1.96-12.76) and 31-49 years old (aOR 1.78, 95\% CI 1.00-2.21) (Table 2).

\section{HBV viral characteristics}

Among 67 HBsAg-positive individuals, 36 (53.7\%) had a blood sample available for HBV DNA measurement and among them, 25 (69.4\%) were on ART including 16 on 3TC and seven on TDF plus 3TC. There were no significant differences in socio demographic characteristics between patients with and without HBV DNA measurement, except for HIV type (85.7\% of HBV DNA measurement in HIV-1 infected patients, $40.5 \%$ in HIV-2 and $63.6 \%$ in HIV-1\&2, $p=0.01$ ). Overall, HBV DNA was detected in eight of 36 patients $(22.2 \%)$ and the median HBV DNA was $42,050 \mathrm{IU} /$ $\mathrm{ml}$ [IQR: 51-79,100,000]. The proportion of patients with undetectable HBV DNA was not significantly different according to ART regimen $(100.0 \%$ with TDF + 3TC (or FTC), $87.5 \%$ with $3 \mathrm{TC}$ and $50.0 \%$ with ART without $3 \mathrm{TC}$ or TDF; $p=0.25)$. The detection rate was not significantly different according to HIV type $(25.0 \%$ in HIV-1, $23.5 \%$ in HIV-1\&2 dually reactive and $14.3 \%$ in HIV-2; $p=1.00$ ), while it was significantly higher in patients not on ART compared to those on ART (45.5\% vs $12.0 \%$; $p=0.04$ ).

\section{HDV co-infection}

Ten (14.9\%, 95\% CI 7.4-25.7) of the 67 HBsAg-positive individuals were tested positive for anti-HDV antibody. Six of them were on ART, including three on 3TC and one on TDF + 3TC (FTC). There was no statistical difference in anti-HDV antibody prevalence according to type of HIV, although the proportion tended to be high 
Table 1 Characteristics of patients at time of blood collection by HIV status - Burkina Faso, Côte d'Ivoire and Mali - leDEA West Africa cohort (2012)

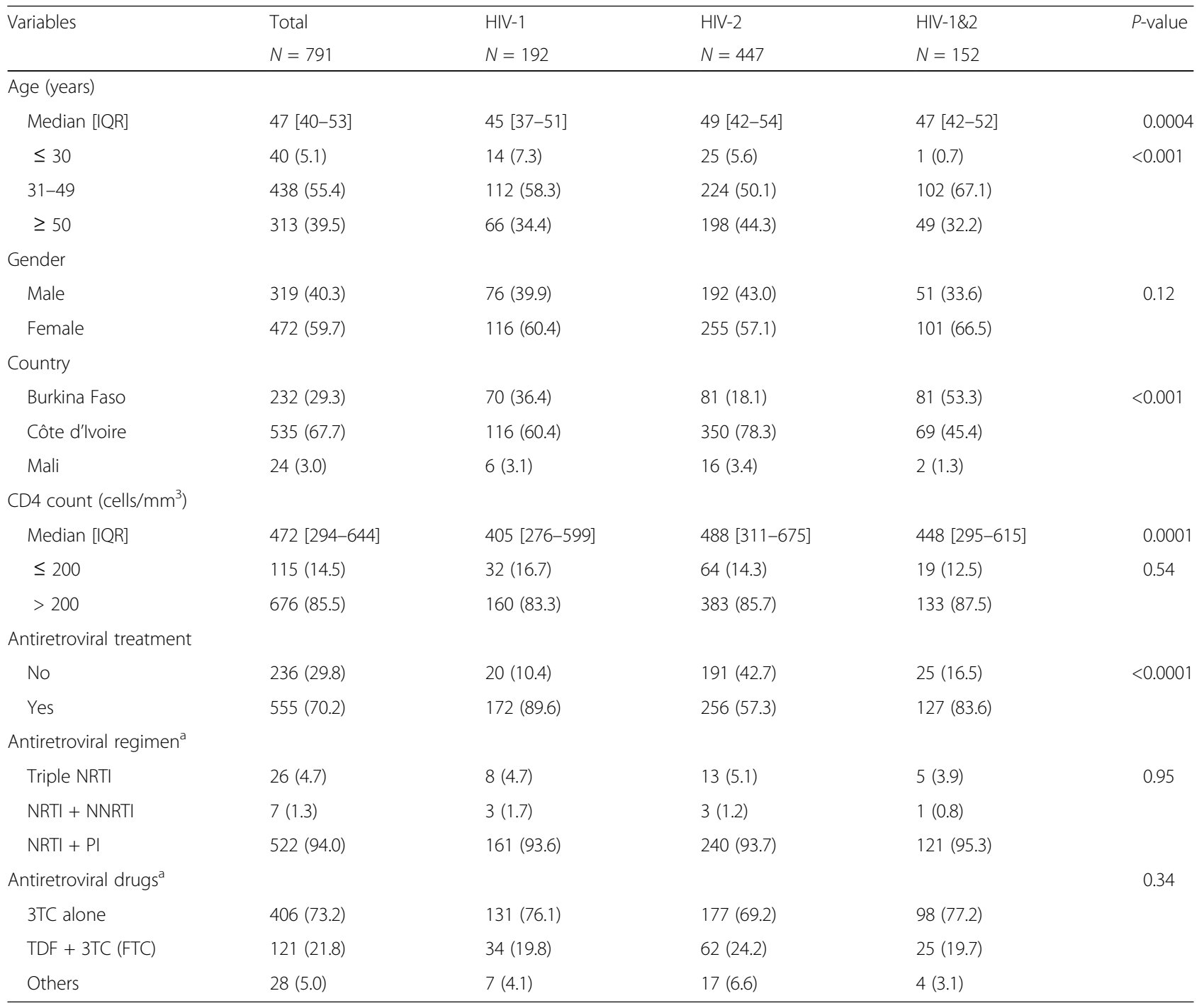

IQR Interquartile range, NRTI nucleoside reverse transcriptase inhibitor, NNRTI Non-nucleoside reverse transcriptase inhibitor, PI Protease inhibitor

${ }^{\mathrm{a}}$ Among patients on ART only

among HIV-1 infected patients (28.6\% in HIV-1, $14.3 \%$ in HIV-2 and $0.0 \%$ in HIV-1\&2 dually reactive; $p=0.15$ ). There was also no statistical difference in this prevalence according to all the other characteristics displayed in Table 1. The prevalence of anti-HDV antibody positivity did not differ according to HBV DNA detectability $(21.4 \%$ in patients with a suppressed HBV DNA vs $25.0 \%$ in those with a detectable HBV DNA; $p=1.00$ ).

\section{Discussion}

In this cross-sectional survey, the prevalence of HBV infection and HBV/HDV co-infection were relatively high, with no statistical difference by country and HIV types. To our knowledge, this is the largest report up to now on HBV/HDV co-infection among HIV-infected individuals in West Africa and the first in the three participating countries (Burkina Faso, Côte d'Ivoire and Mali). There are indeed few published studies in this part of the world [17-19], and none of them, except in Guinea Bissau, has estimated the prevalence by HIV type [19].

Our study has some limitations. First, about $19 \%$ of the patients were considered as HIV-1 \& HIV-2 dually reactive after the retesting. We were not able to differenciate between HIV-1 or type 2 since we did not perform PCR DNA for HIV-1 or HIV-2. Second, we did not document occult HBV infection since HBV DNA was only tested in HBsAg-positive patients. This has probably underestimated the prevalence of $\mathrm{HBV}$ infection. Indeed, in one study conducted in Côte d'Ivoire, 10\% of HBsAg-negative patients had detectable HBV DNA [29]. Third, the lack of molecular data concerning the HDV as HDV RNA testing has become a more compelling tool for recognizing active replication. 
Table 2 Risk factors for HBsAg seropositivity

\begin{tabular}{|c|c|c|c|c|c|c|c|c|}
\hline \multirow[b]{2}{*}{ Factor } & \multirow[b]{2}{*}{ No. of patients with data } & \multirow[b]{2}{*}{ HBsAg positivity } & \multicolumn{3}{|c|}{$\underline{\text { Univariate analysis }}$} & \multicolumn{3}{|c|}{ Multivariate analysis } \\
\hline & & & $\mathrm{OR}$ & $95 \% \mathrm{Cl}$ & $P$ & $\mathrm{aOR}$ & $95 \% \mathrm{Cl}$ & $P$ \\
\hline \multicolumn{9}{|l|}{ Age (years) } \\
\hline$\leq 30$ & 40 & $8(20.0)$ & 3.48 & $1.42-8.48$ & 0.006 & 5.00 & $1.96-12.76$ & 0.001 \\
\hline $31-49$ & 438 & $38(8.7)$ & 1.32 & $0.76-2.30$ & 0.33 & 1.78 & $1.00-2.21$ & 0.05 \\
\hline$\geq 50$ & 313 & $21(6.7)$ & REF & - & - & REF & - & - \\
\hline \multicolumn{9}{|l|}{ Gender } \\
\hline Male & 319 & $36(11.3)$ & 1.81 & $1.09-2.99$ & 0.02 & 2.15 & $1.25-3.69$ & 0.005 \\
\hline Female & 472 & $31(6.6)$ & REF & - & - & REF & - & - \\
\hline \multicolumn{9}{|l|}{ HIV-type } \\
\hline HIV-2 & 447 & $42(9.4)$ & 1.59 & $0.77-3.27$ & 0.21 & 1.66 & $0.85-3.26$ & 0.14 \\
\hline $\mathrm{HIV}-1 / 2$ & 152 & $11(7.2)$ & 1.10 & $0.44-2.72$ & 0.84 & 1.11 & $0.48-2.56$ & 0.81 \\
\hline HIV-1 & 192 & $14(7.3)$ & REF & - & - & REF & - & - \\
\hline \multicolumn{9}{|l|}{ Country } \\
\hline Burkina Faso & 232 & $21(9.1)$ & 1.11 & $0.64-1.91$ & 0.71 & 1.30 & $0.72-2.36$ & 0.38 \\
\hline Mali & 24 & $24(8.3)$ & 1.01 & $0.23-4.46$ & 0.98 & 1.01 & $0.20-4.34$ & 0.93 \\
\hline Côte d'Ivoire & 535 & $44(8.2)$ & REF & - & - & REF & - & - \\
\hline \multicolumn{9}{|c|}{ CD4 count (cells/mm³) } \\
\hline$\leq 200$ & 115 & $13(11.3)$ & 1.47 & $0.77-2.79$ & 0.24 & 1.43 & $0.72-2.84$ & 0.31 \\
\hline$>200$ & 676 & $54(8.0)$ & REF & - & - & REF & - & - \\
\hline \multicolumn{9}{|c|}{ Antiretroviral treatment } \\
\hline Yes & 555 & $51(9.2)$ & 1.39 & $0.78-2.49$ & 0.24 & 1.56 & $0.83-2.95$ & 0.17 \\
\hline No & 236 & $16(6.8)$ & REF & - & - & REF & - & - \\
\hline
\end{tabular}

OR Odds ratio, $\mathrm{Cl}$ Confidence Interval, aOR Adjusted Odds ratio

This may have overestimated the prevalence of HDV co-infection. Fourth, due to low amounts of plasma available, HBV DNA was not performed in all HBsAgpositive patients, and resistance and genotypic tests were not performed. In West Africa region, Genotype E is the predominant genotype [30]. Finally, our study population was selected based on the local identification of HIV-2 and dually reactive patients. The HIV-1 subgroup may thus not be fully representative of all HIV-1 patients in care in the same clinics. Despite these limitations, this study has also two major strengths. First it took place in three different West African countries and second it included a large sample of HIV-infected patients, giving therefore for the first time a global view of the distribution of HBV and HBV/HDV co-infection by HIV type in West Africa.

In our study, the prevalence of HBV was $8.5 \%$ (95\% CI 6.6-10.6) among HIV-infected patients. This result is consistent with previous studies conducted in West Africa that have estimated the prevalence of HBV between $7.9 \%$ and $16.8 \%$ [17, 19, 31-33]. The variation of this prevalence according to studies is possibly due to the HBV vaccination coverage and the specific distribution of some risk factors for HBV infection. Indeed we found that male patients and those $<50$ years old were more likely to be infected with $\mathrm{HBV}$, which is consistent with previous reports [20, 34-36]. The high prevalence of HBV in these two groups could be explained by a greater exposure to HBV through sexual behavior and body mutilations $[20,34,35]$, but also by the early death of older patients infected with HBV during childhood. Indeed, in sub-Saharan Africa, 25\% of adults who have been infected during childhood die from cirrhosis or liver cancer [37]. Other risk factors for HBV infection, such as WHO stage 3 or 4 and CD 4 cell count $<200$ cells/ $\mathrm{mm}^{3}$, were also found in other studies [36].

Only one-third of the patients co-infected with HIV and HBV received a standard-of-care ART regimen including TDF and 3TC (or FTC), two drugs active against both HIV and HBV. The remaining two-thirds were only exposed to lamivudine for about four years, a situation which is known to lead to the development of lamivudine-resistant HBV, from $43 \%$ in year 1 to $>80 \%$ in year 4 [38-40]. Those patients with long-standing lamivudine-resistant mutations may experience worsening liver disease. Since 2013, WHO recommends TDF and 3TC (or FTC) as the preferred NRTI option in first-line ART regimen in adolescents and adults infected with HIV [13, 41], and this 
recommendation is gradually endorsed by countries. This should allow an optimal management of HIV and HBV co-infection, including occult hepatitis. Indeed, according to a recent meta-analysis, up to $90 \%$ of patients receiving such a treatment had a suppressed HBV DNA after three years [42] and resistance to TDF has not yet been described in vivo $[43,44]$. However, even with WHO guidelines for ART use in HIV-infected individuals, including two molecules active on both HIV and HBV, the benefits of HBV screening is still important, including referral for HBV vaccination in susceptible individuals and a better management of those already infected with HBV disease.

Regarding HDV infection, previous studies in subSaharan Africa have reported a prevalence of HBV/ HDV co-infection ranging between $0.0 \%$ and $44.4 \%$ $[17,18,20,45,46]$. More recently, one study conducted in Guinea Bissau found a high prevalence of HDV/HBV co-infection (25.0\%), with no statistical difference according to HIV type [19]. In our study, the HBV/HDV prevalence was $14.9 \%$, not different by HIV type. This large variation of HDV prevalence could be explained by the different settings and populations, but also by the tests used for HDV diagnosis. Indeed, in one cohort of over $200 \mathrm{HIV} / \mathrm{HBV}$ co-infected individuals in rural Tanzania, no confirmed case of active HDV infection (second serology and nucleic acid amplification) was found among the 11 patients who had a positive anti-HDV antibody screening test [46]. Thus, all anti-HDV antibody positive samples should be confirmed with an additional antibody test or an HDV RNA test if possible. The management of this triple infection is complicated. Indeed, the effect of TDF alone or in association with 3TC (or FTC) on HDV replication is controversial according to studies [47, 48]. More research and tools are needed to improve our knowledge on the distribution and management of HBV/HDV co-infection among HIVinfected patients.

Finally, this large and multicenter study showed that like in Guinea Bissau, there was no statistical difference of the prevalence of $\mathrm{HBV}$ or $\mathrm{HBV} / \mathrm{HDV}$ according to HIV types [19]. Thus, the specificity of HIV-2 infection seems to have no impact on the transmission and the rate of $\mathrm{HBV}$ and $\mathrm{HBV} / \mathrm{HDV}$ infection.

\section{Conclusions}

HBV and HBV/HDV co-infection seem to be common in West Africa, irrespective of HIV type and the country. Therefore, the screening of both viruses should be systematically performed in HIV-infected patients to allow a better management of HIV. Follow-up studies are needed to improve our knowledge on HDV infection and to determine the impact of these two viruses on the course of HIV infection, especially now with the universal test and treat policy.

\section{Abbreviations}

ANRS: Agence Nationale de la Recherche sur le VIH/Sida et les Hépatites Virales; aOR: Adjusted Odd Ratio; ART: Antiretroviral treatment; CeDReS: Centre de Diagnostic et de Recherche sur le Sida et les maladies associées; CERS_BF: Comité d'Ethique pour la Recherche en Santé au Burkina Faso; Cl: Confidence Interval; CNER_Cl: Comité National pour l'Ethique et la Recherche en Côte d'Ivoire; DNA: Deoxyribonucleic Acid; ELISA: Enzyme Linked Immunosorbent Assay; HBV: Hepatitis B virus; HCC: Hepatocellular Carcinoma; HDV: Hepatitis Delta virus; HIV: Human Immunodeficiency Virus; HIV-1: HIV type 1; HIV-1\&2: HIV type 1 \&2; HIV-2: HIV type 2; leDEA: International Epidemiological Database to Evaluate Aids; IQR: Interquartile Range; OR: Odd Ratio; PCR: Polymerase Chain Reaction; PI: Protease Inhibitors; RNA: Ribonucleic Acid; TDF: Tenofovir Disoproxil Fumarate; WADA: West Africa Database on Antiretroviral

\section{Acknowledgements}

We thank the fieldwork team, study sites and participants for their effort. We are indebted to all of the HIV-positive people who agreed to participate in this present study as well as to the health workers.

\section{Funding}

The WADA Collaboration is partly funded by the National Cancer Institute $(\mathrm{NCl})$, the Eunice Kennedy Shriver National Institute of Child Health \& Human Development (NICHD), and the National Institute of Allergy and Infectious Diseases (NIAID) of the US National Institutes of Health (NIH), as part of the International Epidemiologic Databases to Evaluate AIDS (leDEA) under Award \# U01Al069919. The ANRS (France REcherche Nord \&sudSida-hivHépatites) supported part of the laboratory work performed within this study.

\section{Availability of data and materials}

The datasets supporting the conclusions of this article are available upon request to the corresponding author.

\section{Authors' contributions}

PAC and DKE designed the study. BKT, GB, MK and DKM contributed to the conception and the design of the study. GB and DKM contributed to the acquisition of the data and the review of the manuscript. PAC, BKT, MK and DKE performed the analyses, interpreted the data and drafted the initial version of the manuscript. GW, GSG, FD and SPE contributed to the conception of the study and revised the manuscript for substantial intellectual content. All the authors read and approved the final manuscript.

\section{Ethics approval and consent to participate}

This survey was designed and performed in accordance with the Declaration of Helsinki and was approved by the national ethics committee of each participating country: the "Comité d'Ethique pour la Recherche en Santé" (Ministry of Health and Ministry of Scientific Research and Innovation) from Burkina-Faso, the "Comité National pour l'Ethique et la Recherche en Santé" (Ministry of Health and the Fight against HIV/AIDS) from Côte d'Ivoire and the "Comité National d'Ethique pour la Santé et les Sciences de la vie (Ministry of Health)" from Mali. All patients were informed and had to give their written consent before being included.

\section{Consent for publication}

Not applicable.

\section{Competing interests}

The authors declare that they have no competing interests.

\section{Publisher's Note}

Springer Nature remains neutral with regard to jurisdictional claims in published maps and institutional affiliations.

\section{Author details}

${ }^{1}$ Département de Dermatologie et d'Infectiologie, UFR des Sciences Médicales, Université Félix Houphouët Boigny, BP V3 Abidjan, CHU de Treichville, Abidjan, Côte d'Ivoire. ${ }^{2}$ Service des Maladies Infectieuses et Tropicales, Centre Hospitalier Universitaire de Treichville, Abidjan, Côte d'Ivoire. 3Programme PACCl, site de recherche ANRS, Abidjan, Côte d'Ivoire. ${ }^{4}$ ISPED, Université de Bordeaux \& Centre INSERM U1219 - Bordeaux Population Health, Bordeaux, France. ${ }^{5}$ Hôpital de Jour, Service des Maladies Infectieuses et Tropicales, CHU Souro Sanou, Bobo Dioulasso, Burkina Faso. 
${ }^{6}$ Département d'Hématologie, d'immunologie et de biologie cellulaire, UFR des Sciences Pharmaceutiques, Université Félix Houphouët Boigny, Abidjan, Côte d'Ivoire. ${ }^{7}$ Centre de Prise en Charge des Personnes vivant avec le VIH, Service de Maladies Infectieuses, Hôpital du Point G, Bamako, Mali. ${ }^{8}$ Department of Infectious Diseases, Bern University Hospital, University of Bern, Bern, Switzerland. ${ }^{9}$ Institute of Social and Preventive Medicine, University of Bern, Bern, Switzerland. ${ }^{10}$ Departments of Medicine \& Global Health, University of Washington, Seattle, USA. ${ }^{11}$ Université de Lomé, Département des Sciences Fondamentales et Santé Publique, Lomé, Togo.

\section{Received: 22 February 2017 Accepted: 26 June 2017}

Published online: 04 July 2017

\section{References}

1. WHO. Guidelines for the prevention, care and treatment of persons with chronic hepatitis B infection, March 2015. Available from: http://apps.who. int/iris/bitstream/10665/154590/1/9789241549059_eng.pdf. Accessed 30 June 2017.

2. Mokdad AA, Lopez AD, Shahraz S, Lozano R, Mokdad AH, Stanaway J, et al. Liver cirrhosis mortality in 187 countries between 1980 and 2010: a systematic analysis. BMC Med. 2014;12:145.

3. De Cock KM, Odehouri K, Colebunders RL, Adjorlolo G, Lafontaine MF, Porter A, et al. A comparison of HIV-1 and HIV-2 infections in hospitalized patients in Abidjan. Cote d'Ivoire AIDS. 1990;4(5):443-8.

4. Evans LA, Moreau J, Odehouri K, Seto D, Thomson-Honnebier G, Legg H, et al. Simultaneous isolation of HIV-1 and HIV-2 from an AIDS patient. Lancet. 1988;2(8625):1389-91.

5. Nkengasong JN, Kestens L, Ghys PD, Koblavi-Deme S, Otten RA, Bile C, et al. Dual infection with human immunodeficiency virus type 1 and type 2: impact on HIV type 1 viral load and immune activation markers in HIVseropositive female sex workers in Abidjan. Ivory Coast AIDS Res Hum Retroviruses. 2000;16(14):1371-8.

6. Rowland-Jones SL, Whittle HC. Out of Africa: what can we learn from HIV-2 about protective immunity to HIV-1? Nat Immunol. 2007;8(4):329-31.

7. Desbois D, Roquebert B, Peytavin G, Damond F, Collin G, Benard A, et al. In vitro phenotypic susceptibility of human immunodeficiency virus type 2 clinical isolates to protease inhibitors. Antimicrob Agents Chemother. 2008;52(4):1545-8.

8. Ren J, Bird LE, Chamberlain PP, Stewart-Jones GB, Stuart DI, Stammers DK. Structure of HIV-2 reverse transcriptase at 2.35-a resolution and the mechanism of resistance to non-nucleoside inhibitors. Proc Natl Acad Sci U S A. 2002;99(22):14410-5.

9. Puoti M, Airoldi M, Bruno R, Zanini B, Spinetti A, Pezzoli C, et al. Hepatitis B virus co-infection in human immunodeficiency virus-infected subjects. AIDS Rev. 2002:4(1):27-35.

10. Hawkins C, Christian B, Ye J, Nagu T, Aris E, Chalamilla G, et al. Prevalence of hepatitis B co-infection and response to antiretroviral therapy among HIVinfected patients in Tanzania. AIDS. 2013;27(6):919-27.

11. Hoffmann CJ, Charalambous S, Thio CL, Martin DJ, Pemba L, Fielding KL, et al. Hepatotoxicity in an African antiretroviral therapy cohort: the effect of tuberculosis and hepatitis B. AIDS. 2007;21(10):1301-8.

12. Wandeler G, Gsponer T, Bihl F, Bernasconi E, Cavassini M, Kovari H, et al. Hepatitis $B$ virus infection is associated with impaired immunological recovery during antiretroviral therapy in the Swiss HIV cohort study. J Infect Dis. 2013;208(9):1454-8.

13. WHO. Consolidate guidelines on the use of Antiretroviraldrugs for treating and preventing HIV infection. Recommendations for a public health approach. Second edition 2016. 2016. Available at: http://apps.who.int/iris/bitstream/ 10665/208825/1/9789241549684_eng.pdf?ua=1. Accessed 4 Nov 2016.

14. Rizzetto M, Hoyer B, Canese MG, Shih JW, Purcell RH, Gerin JL. Delta agent: association of delta antigen with hepatitis B surface antigen and RNA in serum of delta-infected chimpanzees. Proc Natl Acad Sci U S A. 1980;77(10):6124-8.

15. Hughes SA, Wedemeyer H, Harrison PM. Hepatitis delta virus. Lancet. 2011; 378(9785):73-85.

16. Rizzetto M, Ciancio A. Epidemiology of hepatitis D. Semin Liver Dis. 2012; 32(3):211-9

17. De Paschale M, Ceriani C, Cerulli T, Cagnin D, Cavallari S, Ndayake J, et al. Prevalence of HBV, HDV, HCV, and HIV infection during pregnancy in northern Benin. J Med Virol. 2014;86(8):1281-7.

18. Diop-Ndiaye H, Toure-Kane C, Etard JF, Lo G, Diaw P, Ngom-Gueye NF, et al. Hepatitis B, C seroprevalence and delta viruses in HIV-1 Senegalese patients at HAART initiation (retrospective study). J Med Virol. 2008;80(8):1332-6.
19. Honge BL, Jespersen S, Medina C, Te Dda S, da Silva ZJ, Lewin S, et al. Hepatitis B and Delta virus are prevalent but often subclinical co-infections among HIV infected patients in Guinea-Bissau, West Africa: a cross-sectional study. PLoS One. 2014;9(6):e99971.

20. Mansour W, Malick FZ, Sidiya A, Ishagh E, Chekaraou MA, Veillon P, et al. Prevalence, risk factors, and molecular epidemiology of hepatitis $B$ and hepatitis delta virus in pregnant women and in patients in Mauritania. J Med Virol. 2012;84(8):1186-98.

21. Wedemeyer H, Manns MP. Epidemiology, pathogenesis and management of hepatitis D: update and challenges ahead. Nat Rev Gastroenterol Hepatol. 2010;7(1):31-40.

22. Ji J, Sundquist K, Sundquist J. A population-based study of hepatitis D virus as potential risk factor for hepatocellular carcinoma. J Natl Cancer Inst. 2012 104(10):790-2.

23. Egger M, Ekouevi DK, Williams C, Lyamuya RE, Mukumbi H, Braitstein P, et al, Cohort profile: the international epidemiological databases to evaluate AIDS (leDEA) in sub-Saharan Africa. Int J Epidemiol. 2012;41(5):1256-64.

24. WHO. Antiretroviral therapy for HIV infection in adults and adolescents Recommendations for a public health approach 2010 revision. Available from: http://whqlibdoc.who.int/publications/2010/9789241599764_eng.pdf. Accessed 4 Nov 2016.

25. WHO. World Health Organization. HIV test kit evaluations [Internet]. WHO; 2013. Available from: http://www.who.int/diagnostics_laboratory/ evaluations/hiv/en/. Accessed 4 Nov 2016.

26. Barin F, Lahbabi Y, Buzelay L, Lejeune B, Baillou-Beaufils A, Denis F, et al. Diversity of antibody binding to $\mathrm{V} 3$ peptides representing consensus sequences of HIV type 1 genotypes a to E: an approach for HIV type 1 serological subtyping. AIDS Res Hum Retrovir. 1996;12(13):1279-89.

27. Tchounga BK, Inwoley A, Coffie PA, Minta D, Messou E, Bado G, et al. Re-testing and misclassification of HIV-2 and HIV-1\&2 dually reactive patients among the HIV-2 cohort of the West African database to evaluate AIDS collaboration. J Int AIDS Soc. 2014;17:19064.

28. Honge BL, Bjarnason Obinah MP, Jespersen S, Medina C, Te Dda S, da Silva ZJ, et al. Performance of 3 rapid tests for discrimination between HIV-1 and HIV-2 in Guinea-Bissau, West Africa. J Acquir Immune Defic Syndr. 2014;65(1):87-90.

29. N'Dri-Yoman T, Anglaret X, Messou E, Attia A, Polneau S, Toni T, et al. Occult HBV infection in untreated HIV-infected adults in cote d'Ivoire. Antivir Ther. 2010;15(7):1029-34.

30. Forbi JC, Ben-Ayed Y, Xia GL, Vaughan G, Drobeniuc J, Switzer WM, Khudyakov YE. Disparate distribution of hepatitis B virus genotypes in four sub-Saharan African countries. J Clin Virol. 2013;58(1):59-66.

31. Dovonou CA, Amidou SA, Kpangon AA, Traore YA, Godjedo TP, Satondji AJ, et al. [Prevalence of hepatitis B in people infected with HIV in Parakou in Benin]. Pan Afr Med J. 2015;20:125.

32. Musa BM, Bussell S, Borodo MM, Samaila AA, Femi OL. Prevalence of hepatitis B virus infection in Nigeria, 2000-2013: a systematic review and meta-analysis. Niger J Clin Pract. 2015;18(2):163-72.

33. Tremeau-Bravard A, Ogbukagu IC, Ticao CJ, Abubakar JJ. Seroprevalence of hepatitis $B$ and $C$ infection among the HIV-positive population in Abuja. Nigeria Afr Health Sci. 2012;12(3):312-7.

34. Braga WS, da Costa CM, dos Santos IC, Moura MA, Segurado AC. Low prevalence of hepatitis $B$ virus, hepatitis D virus and hepatitis $C$ virus among patients with human immunodeficiency virus or acquired immunodeficiency syndrome in the Brazilian Amazon basin. Rev Soc Bras Med Trop. 2006;39(6):519-22

35. Motta-Castro AR, Martins RM, Yoshida CF, Teles SA, Paniago AM, Lima KM, et al. Hepatitis B virus infection in isolated afro-Brazilian communities. J Med Virol. 2005;77(2):188-93.

36. Vinikoor MJ, Musukuma K, Munamunungu V, Masaninga M, Sikazwe I, $\mathrm{Chi} \mathrm{BH}$, et al. Implementation of routine screening for chronic hepatitis $B$ virus co-infection by HIV clinics in Lusaka. Zambia J Viral Hepat. 2015; 22(10):858-60.

37. Hoffmann CJ, Thio CL. Clinical implications of HIV and hepatitis B co-infection in Asia and Africa. Lancet Infect Dis. 2007;7(6):402-9.

38. Benhamou Y, Bochet M, Thibault V, Di Martino V, Caumes E, Bricaire F, et al. Long-term incidence of hepatitis $B$ virus resistance to lamivudine in human immunodeficiency virus-infected patients. Hepatology. 1999;30(5): 1302-6.

39. Chang TT, Lai CL, Chien RN, Guan R, Lim SG, Lee CM, et al. Four years of lamivudine treatment in Chinese patients with chronic hepatitis B. J Gastroenterol Hepatol. 2004;19(11):1276-82. 
40. Lok AS, Lai CL, Leung N, Yao GB, Cui ZY, Schiff ER, et al. Long-term safety of lamivudine treatment in patients with chronic hepatitis B. Gastroenterology. 2003;125(6):1714-22.

41. WHO. Consolidate guidelines on the use of Antiretroviraldrugs for treating and preventing HIV infection. Recommendations for a public health approach. 2013. Available at: http://apps.who.int/iris/bitstream/10665/85321/ 1/9789241505727_eng.pdf?ua=1. Accessed 4 Nov 2016.

42. Price H, Dunn D, Pillay D, Bani-Sadr F, de Vries-Sluijs T, Jain MK, et al. Suppression of HBV by tenofovir in HBV/HIV coinfected patients: a systematic review and meta-analysis. PLoS One. 2013;8(7):e68152.

43. de Vries-Sluiis TE, Reijnders JG, Hansen BE, Zaaijer HL, Prins JM, Pas SD, et al. Long-term therapy with tenofovir is effective for patients co-infected with human immunodeficiency virus and hepatitis B virus. Gastroenterology. 2010;139(6):1934-41.

44. Gordon SC, Krastev Z, Horban A, Petersen J, Sperl J, Dinh P, et al. Efficacy of tenofovir disoproxil fumarate at 240 weeks in patients with chronic hepatitis B with high baseline viral load. Hepatology. 2013;58(2):505-13.

45. Onyekwere CA, Audu RA, Duro-Emmanuel F, Ige FA. Hepatitis D infection in Nigeria. Indian J Gastroenterol. 2012;31(1):34-5.

46. Winter A, Letang E, Vedastus Kalinjuma A, Kimera N, Ntamatungiro A, Glass $T$, et al. Absence of hepatitis delta infection in a large rural HIV cohort in Tanzania. Int J Infect Dis. 2016:46:8-10.

47. Boyd A, Miailhes P, Brichler S, Scholtes C, Maylin S, Delaugerre C, et al. Effect of tenofovir with and without interferon on hepatitis $D$ virus replication in HIV-hepatitis B virus-hepatitis D virus-infected patients. AIDS Res Hum Retrovir. 2010;29(12):1535-40.

48. Soriano V, Vispo E, Sierra-Enguita R, Mendoza C, Fernandez-Montero JV, Labarga P, et al. Efficacy of prolonged tenofovir therapy on hepatitis delta in HIV-infected patients. Aids. 2014 23;28(16):2389-94.

\section{Submit your next manuscript to BioMed Central and we will help you at every step:}

- We accept pre-submission inquiries

- Our selector tool helps you to find the most relevant journal

- We provide round the clock customer support

- Convenient online submission

- Thorough peer review

- Inclusion in PubMed and all major indexing services

- Maximum visibility for your research

Submit your manuscript at www.biomedcentral.com/submit 